\title{
The problem of China's Environmental protection
}

\author{
Ma Yuliang 1, a , Zhao Quansheng ${ }^{2, b} \mathrm{Hu}$ Shuya $^{3, c}$ \\ ${ }^{1}$ Qingdao University, Qingdao \\ ${ }^{2}$ Qingdao University, Qingdao \\ ${ }^{3}$ List all distinct addresses in the same way \\ a1210588511@qq.com
}

Keywords: environmental engineering; Construction; The difficulty; response

Abstract. with the progress of the construction of the city, in the face of difficulties in environmental engineering construction, only take active measures, further change ideas, implement scientific management, improve the working mechanism, to solve environmental problems arising from the project construction, to really improve people's living environment and quality of life of purpose. Difficulties and countermeasures for the construction of environmental engineering, the author of this paper has carried on the analysis.

\section{Introduction.}

With the continuous development of economy, the increasingly boom of science and technology, all walks of life also gradually tends to the development of modernization, intelligent. This gave the modernization with great power, makes an overall strength of our country into a new stage. But, on the steps of this new environmental pollution problems are more and more serious, and in today's Chinese increasingly rely on new and high technology, that growing car ownership, the electrical appliances use rising, in turn, causes the electric power enterprise, the rise of large quantities of chemical industry is becoming more and more developed, the people environmental protection consciousness weak, such as problems are greatly hindered the development of today's environmental protection cause of strength, in order to fundamentally solve this problem, it is necessary to start from the development direction of the overall construction, development and pollution control engineering, is one of the extremely important link. This means that the pollution treatment engineering company will usher in a new round of challenges and opportunities, both increased competition in environmental pollution control engineering, also to develop the environmental pollution control engineering industry development space. A pollution control engineering companies to be able to win the market competitiveness of enough to seize the opportunity, must be based on national conditions, the development trend of environmental assessment, to ensure the quality of pollution control engineering adequate to meet the demand of the market. Pollution control engineering companies must understand that pollution control engineering is not only a corporate profitability of a project, is the national development and an important cause of environmental protection measures, only when based on national conditions, determine the development direction under the precondition of ensuring project quality, the development of the enterprise will be able to keep up with the pace of The Times, to a more level effectively, can more close to the demand of the market, can more adapt to the development of the market. And enterprises to guarantee the quality of project, it must to enterprise's each work in more depth, make enterprise's each work is based on national conditions. Especially for engineering design, the work was completed with all aspects of the whole project work, played a dominated the direction of the project is an important work, to make enterprises have contracted projects can adapt to the pace of The Times, we must begin from this job.

Only in ensuring the quality of the pollution treatment project design, the construction of the whole project to be able to determine the direction, the remaining stages each work before it can be more clear, fluent, to fundamentally enhance the market competitiveness of enterprises, make the development of the enterprise more true. 


\section{An overview of the paper}

Environmental engineering, the basic content . So far, the people of environmental engineering there are different understanding of the subject. Somebody thinks, environmental engineering is to study the principle and method of environmental pollution prevention and control technology of discipline, mainly is the study of exhaust gas, waste water, solid waste, noise, and pollution caused by radioactive material, heat, such as electromagnetic wave of prevention and control technology; Others think that environmental engineering in addition to the study of pollution prevention and control technology should also include the environmental system engineering, environmental impact assessment, environmental engineering economic and environmental monitoring technology, etc. Although the study of environmental engineering content have different opinions, but from the current situation of environmental engineering development, its basic content mainly have the control of air pollution, water pollution prevention and control of engineering, solid waste treatment and utilization, comprehensive prevention and control of environmental pollution, environmental systems engineering and other aspects.

Everyone through respiration, constantly with atmospheric gas exchange. With an adult one day exchange capacity of about $10 \sim 12$ cubic meters between the gases in the atmosphere. Usually, one of five weeks without food, or five days without drinking water, to be able to survive; But five minutes without breathing will be killed. Say so, especially the clean air is indispensable to people's life, loneliness. However, since the middle of the 20th century, the rising number of species and quantity of pollution into the atmosphere. Have been on the atmospheric pollution caused by the pollutants and may cause people to pay attention to on the atmospheric pollution caused by the material there are about 100 species, including influence surface is wide, serious damage to the environment are mainly sulfur oxides, nitrogen, fluoride, the harmful gas such as hydrocarbon, carbon oxide, and floating in of particulate matter and aerosols in the atmosphere contain a variety of harmful substances, etc. Atmospheric pollutants in some material movement and change, from the nature itself or from the production and consumption activities of human beings. Human production activities emissions of harmful gas management, and industrial exhaust particulate removal principle and method of study is the main task of the project for the control of air pollution.

Water is indispensable to all biological survival and development. Of water contained in the material is very complex, almost all the elements in the periodic table can be found in the water. The wastewater human production and living consumption activities, especially the industrial wastewater and urban sewage water pollution caused by the high number of entering the water.

Physical as a result, the waste water treatment, chemical treatment, biological treatment of wastewater and wastewater treatment methods such as physical and chemical treatment method for wastewater, and make full use of environmental self-purification capacity, to prevent, reduce and eliminate water pollution, improve and maintain water environmental quality, and to formulate the wastewater discharge standard, and utilization of water resources reasonably, strengthening water resources management, has become the main task of the water pollution prevention and control engineering. In the development of human resources, and improving the environment in the process of making products produces solid waste, and any product after consumption becomes abandoned materials, finally into the environment. With the development of human production and improvement of living standards, increasing solid waste emissions, water, soil and air pollution. Duality, solid waste is waste for a production or consumption process, but for another process is often a valuable raw material. Therefore, solid waste treatment and utilization of both for temporarily cannot use waste disposal, such as the municipal waste landfill, incineration and other methods to dispose of; To management or process steps of solid waste, to achieve solid waste recycling, such as the use of mining solid waste, industrial solid waste to make building materials, use of agricultural waste producing methane, etc. Waste gas, waste water and solid waste pollution, it is outcome of combined action of all kinds of natural factors and social factors. Control of environmental pollution must be according to the local natural conditions, find out the laws of the pollutants, migration and transformation, system analysis, the problems of the environment to economic means, management means and technology of combining 
the comprehensive prevention and control measures, reform, production technology and equipment, development and utilization of clean energy, using natural purification ability and so on, in order to obtain the best effect of environmental pollution prevention. Comprehensive prevention and control of environmental pollution is in the waste water, waste gas, solid waste developed on the basis of single governance.

Environmental problems tend to have regional characteristics. Using the principle and method of system engineering, technical measures to prevent and control of regional environmental problems and the overall system analysis, in order to achieve the optimum solution, is the main task of environmental system engineering. Environmental system engineering method can also be applied to different size, grade, section of the system, such as air system (air pollution, atmospheric diffusion model, etc.), surface water system (river pollution, the analysis of lakes pollution and urban sewage recycling), groundwater system, Marine system, and a unit process system in environmental engineering, etc. Environmental engineering is a huge and complicated technical system. It not only study the measures of prevention and control of environmental pollution and hazards, and to study the protection and rational utilization of natural resources, explore the reform production process, development of waste recycling technology, less harm or harmless closed-circuit production systems, and operations research according to the regional environmental management, in order to obtain larger environmental effect and economic benefits, these have become an important development direction of environmental engineering.

The limited natural resources and the growing demand for natural resources, especially the environmental pollution control targets and the contradiction between the demand for energy, encourage environmental engineering of existing technology and the future development of technical development of the environmental impact assessment and environmental impact assessment, provide the basis for protecting natural resources and social resources.

Some people think that predict the progress of science and technology of side effects, is essentially to predict the future of the environment. The United States since the mid - to explore some secondary effects brought by science and technology revolution. Such as building nuclear power station, although compared with the traditional energy industry, carbon dioxide and sulfur dioxide pollution about cut in half, but increased the radioactive pollution. Therefore, resources, ecological and economic development determines the development of environmental engineering in the future trend of dynamic balance.

In environmental science, it is generally believed environment refers to the space around the crowd, and can directly and indirectly affect human life and development of the totality of all kinds of natural factors, but also some people think that the environment in addition to the natural factors, it should also include the relevant social factors.

Some environmental protection laws and regulations in countries around the world, often should protect the environment of the environmental elements or objects, such as atmosphere, water, land, minerals, forests, grassland, wild animals and plants and places of historic interest and scenic area, nature reserves, living place known as the environment, but the environment is not limited to these.

\section{China's current environmental conditions.}

\section{( 1 ) Atmospheric pollution}

1. Pollution situation. Average concentration of sulfur dioxide in $3 \sim 248$ micrograms $/ \mathrm{m} \mathrm{3}$, the national average of 66 micrograms $/ \mathrm{m} 3$. More than half of the northern cities and over a third of the southern city of average more than national secondary standard (60 micrograms $/ \mathrm{m} 3$ ). In the northern city average of $72 \mathrm{micrograms} / \mathrm{m} \mathrm{3}$; The southern city of average of $60 \mathrm{micrograms} / \mathrm{m} \mathrm{3}$. Represented by yibin, guiyang, chongqing southwest high sulphur coal area of the city and the energy consumption 
of shanxi, shandong, hebei, liaoning, Inner Mongolia, henan, shaanxi in some parts of the city of sulfur dioxide pollution is more serious.

2 . Pollution source. Energy use. With the rapid growth of China's economy and the improvement of people's living standards, energy demand is rising. Since 1980, China's coal consumption has increased by more than two times. Raw coal consumption in 1997 reached 1.39 billion tons, is expected by 2000 will increase to 1.45 billion tons. Mainly coal, biomass, oil product energy consumption is the main source of particulate matter in the atmosphere. Fine particulate matter in the atmosphere (less than 10 microns in diameter) and superfine particles (less than 2.5 microns in diameter), the most harmful to human body health, they are mainly from industrial boiler soot emissions from coal stove, and family. Sulfur dioxide and nitrogen oxides in the atmosphere is mostly from the emission source. Industrial boiler coal accounts for 33\% of China's coal consumption, because of its low combustion efficiency, and low emissions, chimney in near ground air pollution as a share of more than its share in the coal consumption. Although households coal usage consumption accounts for only about $15 \%$ of the total, but its share is usually $30 \%$ of air pollution.

Sulfur dioxide emissions in China showed the trend of rapid growth. In the early $90 \mathrm{~s}$, our country for more than 1800, ten thousand tons of sulfur dioxide emissions by 1997, has risen to 23 million tons, predict 2000 will increase to 28 million tons. At present, our country has become the world's number one country in so 2 emissions. Research shows that $87 \%$ of sulfur dioxide in the atmosphere from burning coal in our country. Sulfur content in coal is higher in our country, especially in southwest China, generally in the $1 \%$ to $2 \%$, some as high as $6 \%$. This is cause acid rain pollution in southwest lasted the longest, the main reason why most harmful.

\section{Pollution hazard. Because the serious air pollution in our country, our country's respiratory}

disease incidence rate is very high. Chronic obstructive respiratory diseases, including emphysema and chronic bronchitis, is the leading cause of death, its disease burden is more than twice the average in developing countries. Disease investigation has found that exposure to a certain concentration of pollutants (such as air particulate matter and sulfur dioxide) contained in the health consequences, such as respiratory function recession, chronic respiratory disease, and premature death and hospital outpatient rate and diagnosis rate of increase, etc. In 1989, researchers on Beijing's two residential areas have been studied in the correlation of atmospheric pollution and daily mortality. In these two areas are monitored by high concentration of total suspended particulate matter and sulfur dioxide. If estimation results show that the concentration of sulfur dioxide in air of each 1 times, total mortality increased by $11 \%$; If the concentration of total suspended particulate matter each 1 times, total mortality increased by $4 \%$. Analysis shows that the death, the total suspended particulate matter concentrations, doubled the chronic obstructive respiratory diseases increased mortality by $38 \%$, cor pulmonale, the death rate increases by $8 \%$. In 1992, researchers on the relationship of the shenyang air pollution and daily mortality were studied, the results showed that the concentration of sulfur dioxide and total suspended particulate matter every 100 micrograms $/ \mathrm{m} \mathrm{3}$, total mortality increased by $2.4 \%$ and $2.4 \%$ respectively.

Sulfur dioxide pollution caused by acid such as acid rain, is another important aspect of the atmospheric pollution hazards. Acid rain is atmospheric pollutants such as sulphur and nitrogen compounds) and the product of the chemical reactions between oxygen and water in the air. Burning fossil fuels of sulfur oxides and nitrogen oxides row of the atmosphere, and other chemical substance to form sulfuric acid and nitric acid. These emissions can stay airborne for a few days, well migration hundreds or thousands of miles, and then returned to the ground in the form of acid rain.

\section{( 2 ) Water pollution}

1. Pollution situation. According to the China environment bulletin and water conservancy department, according to a report in 1997, China's seven major river systems, lakes, reservoirs, parts of groundwater polluted by different degree, compared with 1996, the proportion of river pollution, water pollution in the river length increased by $6.3 \%$, and the plentiful increased by $5.5 \%$, and in the 
evaluation of more than 50000 kilometers of the river, the polluted river (42\%), and more than $12 \%$ highly polluted river.

The seven main river water quality worsening in the country. The Yangtze river pollution. Monitoring of the $67.7 \%$ of $\square$ classes and better than $\square$ water, no super $\square$ class of river water quality. But the Yangtze river garbage pollution is heavier, the coastal towns and river boat littering. Piles of rubbish has severely hampered the normal operation of the gezhouba hydropower station, affect the natural landscape of the three gorges.

The Yellow River pollution and block the double pressure. $\square$ for $66.7 \%$ of the river water quality monitoring. The major pollution indicators for the ammonia nitrogen, volatile phenol, potassium permanganate index and bod. Year the longest cutoff of the Yellow River in the $70 \mathrm{~s}$ after 21 days, 1996 for 133 days, as long as 226 days in 1997.

The pearl river pollution is lighter. Monitoring of the $62.5 \%$ of $\square$ classes and better than $\square$ water, $29.2 \% \square$ for river water quality, the rest of the river for $\square$ classes and class super $\square$ water quality, the major pollution indicators for the ammonia nitrogen, potassium permanganate index and total mercury. The huaihe river in stream water quality improved, especially in high pollution of the river improvement is obvious. Water quality is given priority to with $\square, \square$ class, a tributary of pollution is still severe, the level of $52 \%$ of the tributary river for super $\square$ water, $71 \%$ of the secondary and tertiary tributary river $\square$ class for water quality, the major pollution indicators is not above the ammonia and high acid salt index.

HaiLuanHe drainage pollution is serious, the overall water quality is poorer. Monitoring of the $50 \%$ of $\square \square$ class class and water quality. The major pollution indicators of permanganate index, ammonia nitrogen and bod.

Liaohe drainage overall water quality is poorer, the serious pollution. $50 \%$ of the monitoring of $\square$ class for water quality. The key pollution indicators are ammonia nitrogen, total hg, volatile phenol, biochemical oxygen demand (cod) and permanganate index.

The songhua river water quality improvement compared with previous years. $\square$ for $70.6 \%$ of the river water quality monitoring. The major pollution indicators for the permanganate index and volatile phenol and biochemical oxygen demand (cod).

Large freshwater lakes and urban lakes are moderate pollution, reservoir pollution relatively light. Compared with 1996, 1997, chaohu and dianchi lakes pollution levels have increased, the taihu lake. Major freshwater lakes pollution order greatly for: yunnan he most, followed by the chaohu lake (half), nansi lake hongze lake, taihu lake, dongting lake, jingbo, effluents, xingkai lake and the erhai lake. Eutrophication of lakes and reservoirs prominent environmental problem is severe and oxygen consumption increased organic matter. Large freshwater lakes and the major pollution indicators of urban lakes for total nitrogen, total phosphorus, high acid salt index and biochemical oxygen demand (cod). Large reservoir major pollution indicators for the total phosphorus, total nitrogen, and volatile phenol. Part of the lake inventory in mercury pollution. Individual reservoir arsenic pollution.

2 . Pollution source. Industrial waste water. Industrial water pollution mainly comes from the paper industry, metallurgical industry, chemical industry and mining industry, and so on. And in some cities and rural waters surrounding agricultural products processing and food industry, such as wine, tanning, dyeing, etc., also tend to be the main source of chemical oxygen demand (cod) and biological oxygen demand (cod) in water.

City sewage. Although the industrial wastewater emissions during the past ten years of decline year by year, and the amount of sewage is increasing. Compared with 1990 in 1997, city life sewage exactly doubled, to 18.9 billion tons, but our country's urban sewage concentrated rate is only $13.6 \%$. All over the country sewage impact on local water chemical oxygen demand (cod) and biological oxygen demand (cod) is not the same. In shandong province for example, the sewage accounted for $40 \%$ of the total wastewater, and the chongqing municipal sewage is produced $68 \%$ of the local water chemical oxygen consumption and $85 \%$ of the biological oxygen consumption. 
Agricultural waste water. In addition to the agricultural products processing, an indirect water pollution industries in which the crop and livestock and other agricultural production activities is an important effect on water environment. Recent research results showed that the use of nitrogen fertilizer and pesticides is an important source of water pollution. Despite China's fertiliser use compared with the international standard is not particularly high, but due to the extensive use of low-quality fertilizer and a disproportionate share of the application of nitrogen and phosphate fertilizer, potash, its efficiency is low. Of particular note is the use of a large amount of cheap low-quality ammonia fat. The local production of ammonia fat dissolve easily and are washed in water pollution. In recent years, are expanding the scope of application of pesticides, leading to loss of species (birds), water pollution and cause some protected. Livestock farms and biological oxygen demand in water discharge of waste and the main source of e. coli contamination. Meat products (including chickens, pigs, cattle, sheep, etc.) production in the past 15 years rapid growth, followed by a large number of animal waste directly into the water near the farm. In hangzhou bay, a study has found $88 \%$ of the chemical oxygen consumption in water from agriculture, fertilizer and manure contains a large amount of nutrients is the natural ecological balance and inland waters the greatest threat to the quality of surface water and groundwater.

3 . Pollution hazard. The water pollution harm human body health, fishery and agricultural production (through contaminated irrigation water), has increased the spending of clean water supply. Water pollution can also cause harm to the ecosystem, water rich camp oxidation as well as the loss of plant and animal species.

Some diseases associated with human body contact with the water pollution, including ascites, diarrhea, hookworm, schistosomiasis, trachoma and nematode disease, etc. Improve the health condition of water supply can greatly reduce the incidence of these diseases and the harm degree, at the same time also can reduce child deaths from diarrhoea. In general, this kind of disease incidence in our country was lower than those of other developing countries. Compared with other Asian countries income level, water supply and sanitation in China is good, although there is some difference between the urban and rural areas. In 1990, only $1.5 \%$ of the total mortality in China and $3 \%$ of the total burden of disease is the result of common disease is related to the water supply and sanitation (such as diarrhea, hepatitis, trachoma, nematode etc.). By contrast, in our country, chronic obstructive respiratory diseases account for $16 \%$ of the total mortality and $8.5 \%$ of the total burden of disease.

\section{( 3 ) Back to the body of waste pollution}

1. Pollution situation. In 1997, the national industrial solid waste production is 1.06 billion tons, including solid waste production amount of township enterprises 4 . $\mathrm{O}$ one hundred million tons, accounting for $37.7 \%$ of the total quantity, hazardous waste discharge 10.77 million tons, about $1.0 \%$. Industrial solid waste emissions in 19961996 tons, including hazardous waste emissions accounted for $1.3 \%$. Industrial solid waste of the nation's total amount has reached 6.5 billion tons, covers an area of 51680 hectares, which accounted for about $5 \%$ of hazardous waste. The current city life garbage output of about 1.4 billion tons, the national surrounded by two-thirds of the city to the garbage. In recent years, the rapid increase in the amount of plastic packaging, the problem of "white pollution".

2 . Pollution source. Industrial solid waste. Industrial solid waste production in China, 1996 (not including township enterprises) 660 million tons, 9.93 million tons of hazardous waste production. Accounted for 1.5\%; Metallurgical slag, 73.69 million tons, accounting for $11.2 \%$; Fly ash 126.68 million tons, accounting for $19.2 \%$; Slag 77.59 million tons, accounting for $11.8 \%$; Coal 114.25 million tons, accounting for $17.3 \%$, tailings, 188.57 million tons, accounting for $28.6 \%$; Radioactive waste 2.27 million tons, accounting for $0.3 \%$; Other waste 65.99 million tons, accounting for $10 \%$. In producing solid waste industry, mining, electricity, steam supply hot water production industry, ferrous metal smelting and rolling processing industry, chemical industry, non-ferrous metal smelting and rolling processing industry, food, beverages and tobacco manufacturing industry, building materials and other non-metallic mineral industry, mechanical and electrical discharge of electronic equipment 
manufacturing, etc, the largest accounted for about $95 \%$ of the total, which is especially to mining and electric steam discharge hot water supply industry solid waste production is given priority to, accounting for $60 \%$ of the total.

Waste materials. Recycling and utilization of waste materials in China only about a quarter - one-third of the world's advanced level, a large number of renewable resources has not been recycled, erosion, cause pollution. According to statistics, every year, millions of tons of iron and steel scrap in our country, more than 600 ten thousand tons 2 million tons of waste paper, glass not recycling, throw away each year in more than 60 waste dry cell contains 80000 tons of zinc, 100000 tons of carbon dioxide, more than 1200 tons of copper. The economic loss caused by loss of renewable resources every year, 250-250 yuan.

3 . Pollution hazard. Our traditional way of dumping garbage given is a way of "pollution transfer". And existing landfill the number and size of far cannot adapt to the requirement of urban garbage growth, open-air focus stacking condition still is shown most trash, instant and potential hazard to the environment, pollution accidents, problems become increasingly serious.

Occupy a large amount of land, damage to farmland. Piled up in the suburbs of city garbage occupy a large amount of farmland. Without treatment or without strict living garbage directly used in farmland, or only by simple farmers used for farmland, serious consequences. Because this rubbish large fat particles, and contains a large number of impurities such as glass, metal, broken bricks, destroyed the crumb structure and the physical and chemical properties of soil, the soil water retention, fat reduced capacity. According to preliminary statistics, the total use of unreasonable waste fertilizer, every 0.06 hectares, 10 tons of water and fertilizer ability was reduced by more than $10 \%$. Chongqing for use for a long time, without strict processing waste fertilizer, soil mercury concentration has more than 3 times background.

Serious air pollution. In a large amount of trash open-air stacking area, odor, rat-infested, flies NieSheng, there are a lot of ammonia, sulphur pollutants released into the atmosphere. As many as 100 organic volatile gas alone, it contains many carcinogens teratogenic.

Serious water pollution. Waste not only contains pathogenic microorganisms, also in the process of heap corruption will produce large amounts of acidic and alkaline organic pollutants, and the dissolution of heavy metals in the waste to come out, is organic matter and heavy metals and pathogenic microorganism pollution sources. Arbitrary stacked or simple landfilling, its water content and pour into a pile of garbage leachate produced rainwater into the infiltration of surface water and the soil around, will cause serious pollution, surface water and groundwater cause environmental pollution events occur frequently. In guiyang, for example, in the summer of 1983 Wells and hamath wangcheng dirt slope region dysentery epidemic occurred at the same time, the reason is that by landfill leachate pollution of groundwater, value of more than 770 times more than drinking water standard and e. coli bacteria content to exceed bid 2600 times.

\section{Problems of environmental engineering}

Environmental engineering is a comprehensive strong science, which covers the content is more, in particular, is engaged in research and prevention and control of environmental pollution and improve the environmental quality of science and technology. Due to the environmental engineering in our country is still in its infancy, so that there are many problems, embodies in the following aspects:

( 1 ) The lack of professional management talents. Look from the overall situation in our country, although the public's environmental awareness has increased significantly, but the understanding of environmental engineering management is more obvious, though, there appeared a lot of environmental pollution control engineering all over the country, but the actual running effect is not ideal. Lead to the root cause of the problem lies in the serious lack of environmental engineering professional management personnel, and professionals follow-up training work has failed to keep up 
with the needs of the development of practical, caused part of the management of technical levels stagnate, it hardly conducive to the development of environmental engineering in our country.

\section{( 2 ) Lack of publicity. At present, the domestic for environmental engineering management} propaganda work less, causing a lot of you didn't get make full use of resources. Caused by a lack of publicity, make some environmental engineering management information can not be released to the public in time, some of the pollution to the environment serious engineering failed to be found, not only destroyed the environment, but also indirectly lead to a lot of waste of resources.

( 3 ) Environmental engineering technical standard is not perfect. In recent years, the growing environment of domestic construction projects, all sorts of problems also emerged, including comparison with landscaping construction lag, sewage treatment can not meet the requirements of city development, living garbage misconduct, few technologies to reduce emissions, and so on. The existence of these problems is not only conducive to the improvement of residents' living environment and improve the quality of our life, but also seriously affected the sustainable development of environmental engineering. Causes of these problems is the environment project of incomplete technical specification standards, can play a guiding role in engineering construction.

( 4 ) Management system is not sound. Because in the field of environmental engineering research in China starts late, the related management system is not sound, this to a certain extent, restrict the development of environmental engineering. At the same time, matching with environmental engineering management laws and regulations are not perfect, not with the current environmental engineering measures for the management of effective connection, lead to environmental engineering management work to develop smoothly.

\section{( 5 ) Investment is not enough. Both in environmental engineering, construction and project} management needs the support of a large number of people, goods, content, and from the point of view of the current overall situation, our country engineering construction management in the environment of the serious shortage of investment, it not only directly affect the engineering projects, but also restricted the management work. If you can't very well solve the problems of the commitment, is bound to affect the construction and development of environment engineering.

\section{Countermeasures}

\section{( 1 ) Encourage social diversified investment, strengthen the construction of environmental}

engineering of the construction of the system. Urban environmental engineering is an engineering cost is larger, in the development of not only requires the government to provide the necessary financial support, and also encourage socially pluralistic investment strength to participate in them. Including in the construction of urban sewage, urban living garbage harmless treatment and construction of urban landscaping project and needs to have more specification system to maintain a set of system. Let more powerful enterprises involved in urban environment construction, is advantageous to the benign operation of the urban environment project. Establish the necessary environment guidance mechanism, strengthen the propaganda, increasing government rewards to the participants and maintain, arouse the enthusiasm of their construction, and promote the development of the whole urban environmental construction.

\section{( 2 ) Comprehensive utilization of resources, the development of secondary resources. With the}

speeding up of urbanization, the urban population increase. All kinds of increasing amount of waste, recycling the importance and the urgency of the use of secondary resources, therefore, the use of secondary resources as a national priority for economic strategy, and makes the utilization of secondary resources rise year by year. In China every year, more than 300 ten thousand tons of iron and steel scrap, more than ten thousand ten thousand tons of waste paper, more than 200200 tons of waste glass, more than 70 ten thousand tons of waste plastics, more than 30, ten thousand tons of chemical 
waste, more than 30, ten thousand tons of waste rubber is not recycling, a large number of resources available as waste erosion, and severe environmental pollution. Therefore, recycling utilization of secondary resources, comprehensive utilization of resources in our country's potential is very big, very difficult task.

( 3 ) Material recycling and comprehensive utilization of waste. The production of "three wastes" is essentially loss during the production of raw materials, intermediates and by-products, especially the main industry of our country agricultural chemicals, fuel utilization rate of raw materials generally only $30 \% \sim 30 \%, 60 \% \sim 70 \%$ in the form of "three wastes" discharge into the environment. In the process of production is relatively easy to implement water closed-circuit circulation, water supply, water and well water integration, multi-purpose monohydrate, the points of use, water reuse. Our country has successfully developed the use of phosphorus gypsum range of sulfuric acid and cement, nitrous acid by using nitric acid tail gas production system, production by sulfuric acid tail gas system of sodium sulfite, from pyrite slag recovery of gold, silver, iron, from wastewater in the extraction recovery dimethoate rogor synthesis, etc., are of great use value "three wastes" comprehensive utilization technology.

\section{Acknowledgements}

I would like to express my gratitude to all those who helped me during the writing of this thesis. My deepest gratitude goes first and foremost to Professor Zhao Quansheng, my supervisor, for his constant encouragement and guidance. He has walked me through all the stages of the writing of this thesis. Without his consistent and illuminating instruction, this thesis could not have reached its present form. I also owe my sincere gratitude to my friends and my fellow classmates who gave me their help and time in listening to me and helping me work out my problems during the difficult course of the thesis.

\section{References}

In Chinese

[1] He Yi. Implement the scientific concept of development which is building a green ecological [J]. Journal of jiangxi energy, 2006 (04).

[2] Sun Xiangyan.City life garbage disposal at home and abroad situation [J]. Journal of coastal engineering, 1999 (04).

[3] Li Jinxin. Extraction in environment tort relief problems and solutions [J]. Journal of zhengzhou railway vocational and technical college, 2006 (03).

[4] Zhang Baofeng. Garbage power generation of the advantages and existing problems of [J]. Journal of northwest electric power technology, 2005 (03).

[5]Ning Jing, Lu Min. Affected by water stress problems of artificial wetland plants and countermeasures [J]. Journal of shandong construction university, 2011 (02). 